\title{
FACTORS INHIBITING FEMALE MANAGERS' AdvanCEMENT To SENior POSITIONS
}

\author{
IRIS RON*
}

\begin{abstract}
This literature review will examine the internal and external factors that hinder female managers' advancement to senior positions in the Israeli labor market. The cultural framework consists of several main elements that guide gender roles. During the COVID-19 period, women experienced more difficulties associated with the new constraints and guidelines than men in workplaces.

The review is divided into internal and external factors in four main areas: sociology, economics, human capital, and legislation.

The glass ceiling for a female manager is created in an organization whose structure is not suitable for the inclusion of women and mothers. From an early age, boys and girls experience different attitudes according to gender, social expectations, perception of themselves, social disparities, economic dependence, and discrimination.

Changing the perception of gender roles in all areas of life may change workplace culture. Legislation and enforcement may create a gender balance in public and private sectors.
\end{abstract}

Keywords: female management, senior positions, glass ceiling, career, professional pipeline, wage differences, economics, sociology, human capital, legislation, inhibiting factors, COVID-19

\section{JEL Classification:}

\section{INTRODUCTION}

The background for the present paper is the data from the Israeli Central Bureau of Statistics (CBS) showing that women make up $47 \%$ of the labor force in the market according to 2014 survey results. Of all management positions, $32 \%$ are held by women. The proportion of women in senior management of companies listed in the Tel Aviv 100 Index is 19.4\%, and the percentage of women among board members is only $18.2 \%$. Of these board members, $6 \%$ are CEOs, and $4 \%$ are chairs of the board (Aharoni, 2015).

\footnotetext{
* Alexandru Ioan Cuza University, Department of Economics and Business Administration, Iaşi, Romania, 21 Hadas, Yokneam Ilit 2066811, Israel, E-mail: iris@comutech.co.il
} 
Although women make up $47 \%$ of the workforce, which nears equality, most are not managers. Women have been shown to take on responsibilities and tasks associated with senior positions, such as vice president, but are ranked according to their middle management title, as are their salaries (Wall Street Journal, 2020).

According to these data, the situation in Israel with regard to the status of women in senior positions is still far from being in gender balance (Aharoni, 2015).

External factors begin at the macro level, in organizations' hierarchical military structure (Sasson-Levi 2017). Other external factors that prevent women's advancement are an organizational culture representing inherent perceptions of language, division of roles, relationships, and even the tone of speech. At the micro (individual) level, another external factor that prevents many women from advancing in their professional roles is that they are also current or future mothers (Bar Zuri et al., 1997).

This paper will address gender differences in the workplace and the limitations women face in reaching senior positions in Israel. Some of these limitations stem from the State of Israel's character since its independence, and some are international. In addition, the primary professional victims of COVID-19 constraints are women whose promotions have been halted, and whose ability to pursue a master's degree, which is the door to a senior position, was blocked for economic reasons (35\% of students surveyed in Israel indicated that the corona crisis created economic difficulties for them, while 20\% dropped their studies as a result) (Ilan, 2020). Another COVID-19-related reason for the lack of promotion is that women cannot continue to work when there are no educational solutions for children outside the home (Hasson and Ben Eliyahu, 2020).

\section{MethodS}

The paper's structure is based on the classification of inhibiting factors by external and internal influences on the promotion of female managers.

The main reasons women do not advance to senior positions are divided according to the main areas ranked from wide to narrow perspectives:

1. Sociology

2. Economics

3. Human capital, with an emphasis on female management.

The literature review is based on the following key concepts and their interpretations:

- Affirmative action (for women) - The process of getting women into work positions in order to create a gender balance (Kramar, 1998) 
- Aspirations and expectations - A desire to hold or advance to a senior position (Herrbach and Mignonac, 2012)

- Board of Directors - Group of directors and consultants responsible for managing the corporation (Cambridge University, 2020)

- Career - The professional path of the person in the field(s) in which they work (Cambridge University, 2020)

- Female management - The typical management style for women that contrasts masculine management (Gabdreeva and Khalfieva, 2016)

- Female professions - Areas of practice that are in a gender imbalance that favors the female side

- Glass ceiling - The barrier that women reach in terms of wages, the share of senior positions, and occupational crossover (Oakley, 2000)

- Higher education - Academic studies beginning with a bachelor's degree; a condition for promotion is a master's degree or higher (Cambridge University, 2020)

- Mentoring - Accompanying an employee at the beginning of his or her career by a veteran in the field, with the provision of orientation and tips for success (Cambridge University, 2020)

- Middle management - Management with limited responsibility for employees or a specific issue (Gabdreeva and Khalfieva, 2016)

- Mothers in the workplace - Women who currently or may in the future take care of children, and who want to balance work and home life (Barry, 2019)

- Neocolonialism - Hierarchical structures created by military regimes that operated in countries that were conquered by empires; the State of Israel continued with these structures and methods for the independent management of an economy (Sasson-Levi and Misgav, 2017)

- Networking - Connections and relationships between people who are aware of the employee's abilities, and can influence professional development (Cambridge University, 2020)

- Professional pipeline - A person's career path from the beginning of school until reaching a target position (Schweitzer et al., 2011)

- Self-realization - Expression of abilities, and specialization in them to achieve personal goals (Olson, 2013)

- Senior - A position given to a manager with the rank of vice president and above (Cambridge University, 2020) 
- Wage differences - A comparison between the pay given to men vs. women for the same hours of work in the same field with the same level of education and years of experience (Payscale, 2020)

\section{RESULTS AND DISCUSSION}

\subsection{Inhibiting Factors in Sociological Aspects of Career Development of Female Managers Toward Senior Positions in Israel}

\subsubsection{External sociological aspects inhibiting advancement of women to senior positions}

External factors that prevent women's promotion to senior positions are rooted in the following:

1. "Glass ceiling" - The glass ceiling is the barrier that women reach in terms of wages, the share of senior positions, and occupational crossover, relative to men (Oakley, 2000).

2. Organizations' hierarchical military structure is fundamentally masculine (Sasson-Levi and Misgav, 2017).

3. The influence of cultural perceptions in creating gender differences in the workplace creates situations in which women are often silenced (Reardon, 2015; Fisher, 1991).

4. Lack of networking and organizational politics for women: women often feel forced to maneuver between gender loyalty and the struggle to remain in their jobs (Duguid, 2011).

5. The responsibilities of motherhood outweigh the importance of economics and self-realization (Zainzinger, 2012).

The glass ceiling is a metaphor describing an invisible barrier to the advancement of careers - in this context, of high-achieving women. It reflects corporate policies and practices in training and career development (including promotion and compensation) which do not allow women to reach senior ranks. Glass ceiling culture dictates to women the perception of their status in society and the workplace (Flippin, 2017; Oakley, 2000).

Women need experience in areas such as operations, manufacturing, or marketing, which are generally not in the career track of female managers. Women rarely choose professions considered "only for males." The experience required as a necessary condition for the position of CEO dictates a specific line of professional development and other senior management positions. Often these policy difficulties are not addressed in the lower ranks of management. Subsequently, when women 
rise to positions closer to the top later, they often find themselves excluded from upper management levels due to improper tracking earlier in their careers (Oakley, 2000; Morrison, 1992).

Oakley (2000) argued that there are several conditions for creating employment diversity in the workplace:

1. An understanding of the rationale behind occupational diversity at all levels of the organization.

2. Leadership training courses for women interested in taking part in the process of increasing employment diversity in their workplace, including promoting women to the ranks of upper management.

When women fully participate in the labor market, companies' profitability increases due to the following reasons (International Finance Corporation, 2013):

1. Women enable access to new markets and diverse sectors.

2. Women take fewer risks in management and strategic decision-making.

3. Women bring higher education levels, extensive areas of knowledge, resourcefulness, creativity, and multi-tasking.

For example, a case study: "E" is a female manager who became vice president at a factory. She was initially in a "female" profession, in the position of an educational consultant, and realized that her professional path would lead to being only a school principal. She decided to move to the industry and started her career from the bottom up. She already had a master's degree, so she progressed to become a human resources vice president at an industrial company where she worked (unpublished interview).

The neo-colonialism theory suggests that organizations' hierarchical military structure is fundamentally masculine, even though organizations have been defined as gender-neutral (Sasson-Levi and Misgav, 2017). Neo-colonial structures in Israel offer preservation of old hierarchical patterns, from the high commander's level to middle commander to soldier. Since the British Mandate era, officers in the rank of sergeant were the top managers of the entire state organization. This model is duplicated in the industry even today, e.g., the title of an individual responsible for the safety or security of workers in the industry is called "officer" ("katzin" in Hebrew), which carries a rank equivalent to that of sergeant (Sasson-Levi and Misgav, 2017).

Neo-colonialism is a barrier to women's professional advancement due to several reasons: 
1. This hierarchical structure is generally not suitable for women, who tend to use other styles of handling projects. Rather than using authority as a way to manage workers, women tend to delegate tasks (Kanter, 1977).

2. From the early days of Israel, military and militancy are combined in society. The "militant agenda" reflects the male agenda that excludes women from the discourse. Although women take part in military service at the age of 18 (generally until 20), most are not a part of the combat arena. Therefore, men consider them to be not part of the primary military conversation - and by default, male - circle (Eiran-Yona, 2013).

3. Neo-colonialism separates Jewish and Arab women's identities, and does not let their equality struggles join together. This situation is due to the tension between the two peoples for many generations (Sasson-Levi and Misgav, 2017).

4. The influence of cultural perceptions in creating gender differences in the workplace creates situations in which women are often silenced (Reardon, 2015; Fisher, 1991).

In many cases, when interpersonal discourse is held, it is conducted in a way that the male voice sometimes trumps the female voice, which tends to be more delicate (Reardon, 2015).

Even independently of their role, women's voices often are not heard or are completely ignored. The results of a survey conducted by Fischer (1992) among men and women in senior positions in large corporations justify this statement about silencing women. Women in senior positions claim that opportunities to be heard are not given by their male counterparts, who do not listen to them. If this is senior executives' experience, there is little chance that most women in the workplace will be heard. Under these conditions, it is not surprising that only $2 \%$ of CEOs answered in the affirmative when asked whether it is likely that their company will have a female CEO in the next decade (Fisher, 1992).

One of the reasons women are not promoted is the lack of support or loyalty from their peers, due to power struggles for fear of their status and maintaining their place and roles in the organization (Duguid, 2011). There are several reasons for this:

1. The number of positions for women is relatively small, so the struggle to survive is challenging.

2. There are always power struggles between men, but it is not acceptable for women to fight.

3. The female manager may feel that her value is threatened by another woman who might be considered better and with more credentials. 
The responsibilities of motherhood outweigh the importance of economics and self-realization. As the working class develops and more women join the workforce, women's ability to produce a balance between family and career will grow and help in successful and continuous employment (Rout and Rout, 2002). Now they are facing occupational stress.

Stress at work can adversely affect family life and vice versa (Rout and Rout, 2002). In society, the expectations of women and especially mothers have remained the same over the past decades. Therefore, motherhood still presents a barrier that affects women's professional advancement.

1. The career expectations stem from women's conscious decisions to pursue different career paths from men. It reflects their values (e.g., maintaining the family), and thus gender differences are created (Wang and Degol, 2017).

2. Human capital theory suggests that women tend to prefer employment conditions that enable work-life balance over salary and promotion. Further, women may consistently invest less in the education and work experience necessary for their advancement, and more in their children (Schweizer et al., 2011). For example, "I" preferred to study education to be a teacher so that she can finish her workday in the afternoon, rest, pick up her children from kindergarten, and spend holidays with the family (since there are no studies at those times) (unpublished research).

According to existing research, most women in management positions do not consider moving up the management ladder to senior positions (Brier-Garb et al., 2017). Society's expectation of women is caring for children as a primary priority, careers as a secondary priority.

1. Even when women are more talented and have higher education levels and aspirations for advancement than their male peers, their concerns may be in other areas: their relationships, their place in the family and home, and their duty to care for their children (Herrbach and Mignonac, 2012).

2. There is a stereotype about women and their place in the workplace that geography is a barrier, as it is expected that a woman would not work too far from home if she needs to take her child from school/kindergarten in the middle of the day (Dagblad, 2019). Kindergartens in Israel are sometimes located far from the workplace, due to the placement of children in state kindergartens by area of residence) (Ministry of Education, 1959). 


\subsubsection{Internal sociological aspects inhibiting advancement of women to senior positions}

Women tend to have low expectations and aspirations regarding their success. A case study conducted by Axelrod (2017) indicates that a woman who was told as a child that she can reach any goal she wants is likely to advance to a higher level in the organization in the future, given that there is a match between her performance level and expectations.

The following are potential barriers:

1. Fear of running for senior positions: women are afraid to apply for a senior position if they think they do not have $100 \%$ of the job description qualifications. Even when women know they can do the job well, they assume they may not be able to pass the resume screening or interview stage due to the lack of some of the skills stated to be required for the job (Mohr, 2014).

2. The perception of the management position as too challenging, and the responsibility for the profit and loss is too heavy: women tend to not feel comfortable applying for a senior position. Further, there is a lack of awareness of the importance of mentoring and networking in the organization (Barry, 2019).

3. Women are satisfied with low wages and part-time jobs when working conditions are favorable: women more than men tend to gravitate towards low-level and low-paying part-time jobs that offer flexibility. At the senior level, they would be expected to work full-time, and work culture does not provide clear policies and procedures for balancing private life and work (Grant et al., 2006).

4. Women feel alienated in executive meetings characterized by masculine organizational culture: women describe the behaviors that seem disturbing to them. They say that their voices are not heard and that their words are interrupted or ignored altogether in meetings. Important working and networking meetings also often do not occur during the workday, but rather during male-dominated activities outside of the workplace (e.g., in pubs, at football games, or on the golf course) (Stocking, 2020).

5. Women tend to choose to remain silent so as not to provoke conflicts in the workplace: research by Milliken (2003) of New York University found types of concerns raised by the respondents indicating the influence of their decisions to remain silent. The most common concern was to appear negative or be labeled as a serial complainant (30\%). Some thought that if they spoke out, they would not be seen as team players. “A person's strength comes when 
people find them pleasant, reliable, and easy to work with" (Female, Investment Banking Firm). The second most commonly expressed fear was from hurting work-related relationships. Many survey participants (27.5\%) said that talking about problems that bother them could hurt relationships with colleagues or bosses they rely on to get important information. They were afraid that they will no longer like them or will stop thinking they are trustworthy. The biggest fear is avoidance (Female, consulting firm). The third fear is that others will not listen or do anything anyway, so it is not worth the effort (25\%). Some say, "why bother telling when nobody is listening?" and some say, "it probably won't be worth taking the risk." The last fear is from revenge or punishment $(22.5 \%)$, including losing the job or promotion opportunities. "Managers value loyalty above all else ... If you were okay, and you never said anything controversial, you would advance in the organization" (Female Chemist, Biotechnology Company) (Milliken, 2003).

6. Women tend to have low self-confidence and be outwardly sensitive to criticism. In contrast, men tend to show more confidence. Male managers, who have been taught to move away from their emotions, are therefore perceived as having greater abilities (Fischer et al., 2018).

7. Women are sensitive and, therefore, more considerate, but tend to demonstrate high vulnerability. The related perceived lack of authority tends to undermine the trust of subordinates and their commitment to comply with directives (Fischer et al., 2018)

\subsection{Inhibiting factors in economic aspects of women's careers \\ 3.2.1 External economic inhibiting factors in career development}

Women's career advancement track is different from that of men. One of the known reasons for their different trajectories is called "leaky pipeline syndrome." While men's advancement is described as a planned pipeline starting from the period of study until they are promoted to senior positions, in women, of those starting in the engineering, computer, mathematics, chemistry, etc. study track, only $10 \%$ will reach senior positions. The reasons for dropping out along the way are internal and external and are discussed elsewhere in this paper (Ministry of Economy and Industry, 2019).

There are fewer positions for a senior management rank in fields that tend to be considered "female." According to a study using 1950-2000 data from the United States Census Bureau, when women dominated traditionally male professions in the same sector, wages decreased significantly, independently of education level, work experience, skills, race, and geography. Every decade, a $10 \%$ increase in the 
proportion of women in that sector resulted in an up to 5\% decrease in hourly wages (Levanon et al., 2009). A profession characterized as male tends to have more prestige and thus has a senior position reserved on the management team to which one can be promoted. Once an occupation starts to be feminized (i.e., takes on more females), the wages/salaries decrease, as do promotions, and as a result, there is rarely a senior place in the field (Hedreen, 2019).

The problem is that women agree to fulfill everything included in the VP's position but without the rank and salary commensurate with the size of the job and responsibilities. The basic premise is that a woman will perform the required work and even more to prove herself and demonstrate actual results (Hedreen, 2019).

In its early days, the computer industry was mainly used for accounting and programming, considered female professions. As the field evolved and the technology became more complex to operate, employees with higher STEM skills were required, and the field became male-dominated (Orbach, 2016). As a result, salaries increased, as did management roles. Today the technology industry is characterized by male culture (Hedreen, 2019).

According to a study, $30 \%$ of jobs in positions typically filled by women were filled by men from 2011 onward; $27 \%$ of all professions dominated by women, such as accountants, education managers, interior designers, human resources managers, pharmacists, and cooks, are currently held by male workers (Hedreen, 2019).

Flat wages accompany the growth rate of women's participation in the workforce. As wage levels rise, the growth curve of women's participation in labor flattens out. It is evident that in the higher grades, the increase in wages and participation of women stops (Galka, 2015).

Women's wages are lower than those of men in the same field and in the same position (Payscale, 2020). This phenomenon is seen in Israel and around the world, and cannot be explained by the stereotype of fewer working hours. In practice, a woman's hourly wage is lower than a man's hourly wage (e.g., $\$ 0.70-\$ 0.92$ for every $\$ 1$ a male makes) (Payscale, 2020). Further, women can generally give less overtime than men due to family and household obligations. Women gain less experience than men because the former are often forced to leave work due to childbirth and childcare. Women also participate less in courses than men because studying is a privilege for those who can spend many hours away from family and children and ultimately bring more money. Given the expense of advanced education, with the importance of degrees in career promotion, this creates a vicious cycle that prevents gender equality (Bar Zuri et al., 1997). 


\subsubsection{Internal economic inhibiting factors in career development}

A crucial internal factor for women is to be significant and valuable and to contribute to the global economy; however, this need is often not expressed. When choosing a profession at the beginning of their careers, women indicate the importance of doing the work itself as best as possible and do not aim for management in their field. Therefore, they remain in their working roles and do not advance to management roles (Bar Zuri et al., 1997).

Women currently do not have egalitarian economic involvement. They make up two-thirds of the world's workforce, but receive only $10 \%$ of global income, and hold only $1 \%$ of global assets. Meanwhile, they make up about $70 \%$ of the world's poor. Further, women worldwide are often engaged in three roles simultaneously: raising children, household chores, and paid work to support the family (Jalbert, 2010).

Ironically, studies show that companies with women in senior management produce a higher profit line, especially when there is gender balance in management in general. The point of change in public companies is created when at least three women are present on the board of directors, generally meaning that at least $25 \%$ of all board members should be women (Deshe, 2020).

Women report a lack of knowledge in the areas of business and activity of the workplace (e.g., engineering, computers, chemistry, sales, and marketing). For example, the areas in which they have less experience include the industrial field where the company is engaged, sophisticated technical practices in high-tech, or business knowledge in sales and marketing. This lack of knowledge undermines their confidence and does not allow them to express their opinions at management meetings in making strategic decisions for the organization. In the intervention program for gender equality in the public sector, enrichment courses for female leadership in organizations will be budgeted, including learning areas relevant to their ministry's field of practice. The enrichment process for women must include business knowledge in the corporate arena, as detailed by the Israeli Ministry of Economy and Industry (Mizrahi Simon, 2015).

\subsection{Inhibiting factors of female human capital in management and the integration of women at the senior level}

3.3.1 External inhibiting factors in the integration of women at the senior level

Women are in managerial roles but not in senior positions. Even in sectors where the vast majority are women, most men will be found at the top level. As in the United States, the under-representation of women in senior positions is 
characteristic of Israel. As of 2014, only $40 \%$ of the top managers and only $15 \%$ of CEOs were women. This situation is also prevalent in the public sector, though most employees therein are women. In 2015, only $16 \%$ of CEOs in the civil service were women (Hermon et al., 2018), even though female management has often been observed to be more effective than male management. For example, women can maintain relationships and speak at eye level, especially with Generation Y, which is a significant advantage (Gallup, 2015). The lack of social recognition of these benefits stems from the prejudices and personality shaping of men and women from childhood, along with other previously detailed barriers such as gender-based discrimination. This situation may change in the future, due to efforts against discrimination (Hermon et al., 2018).

\subsubsection{Internal inhibitory factors in the integration of women at the senior level}

Women usually do not use their authority in management, while men are required to express assertiveness in this context. If a woman uses authority, i.e., commands instructions to her subordinates, it is not well received, neither by men nor by women. Women also do not respond well to authoritative behavior from a female boss. Women are expected to be soft, explanatory, and motherly rather than forceful. Otherwise, they are attributed traits of those who cross the line of fair and equal relationships, especially by Generation Y. Many women believe that their focus on leading a process through a more personal and encouraging management style is not perceived as achieving the desired result when it comes to promoting them in the organizational hierarchy. On the other hand, men are expected to be strong, leading, determined, and authoritative; otherwise, they are characterized as weak, hesitant, and lacking in leadership skills, and tend to hide other sides of their character (Australian Government Department of Social Services, 2008).

Women's quiet and soft voice does not support their status in loud arguments and verbal confrontations; when there is an argument between people, the men's bass voice outweighs women's voice (Reardon, 2015). Women avoid raising their voices for the following two reasons: (1) politeness requires women to not raise their voices; and (2) women's voices tend to be distorted ("shrill") when raised, which can reveal vulnerability rather than intensity. The theme of the voice is rooted in cultural perceptions, which in turn, are rooted in the culture of discourse between people. The general tendency of men is to dominate mixed discussion groups. Beyond the need to be aware of this tendency, it is argued that businesses need to find ways to avoid such situations that cause gender bias (Reardon, 2015). 
Perhaps in a managed discourse culture, everyone will be able to speak for a limited time by a facilitator. As it takes place in virtual encounters using video conference platforms, there will be almost no differences between women and men due to their voices. According to Krupnik's article on the discussion patterns of the various genders, female students tended to have equal exchanges during the discourse. In men's discussion groups, the conversation was more like a competition: most added personal stories and get more attention, or raised their voice to create superiority over others in the discussion (Krupnick,1985).

\subsection{Legislation}

In Israel, there is a "Civil Service Law," which deals with the field of "appointment to public positions" under section 02A (1958). Under this law, the government enforces women's representation in all departments and divisions, and in all ranks and professions of all government ministries. This law is about representation, not absolute equality, and is about relative equality (i.e., if women staff $45 \%$ of public service positions, then representation in senior positions will reflect this same proportion). The law demands to do as much as possible and even take "corrective action" already at the job acceptance stage, and of course, at the job promotion stage (Civil Service Commissioner, 2019).

The department responsible for human capital management in the public sector is the Civil Service Commission. Within this office is the Division for Gender Equality and the Advancement of Women (Wexelman, 2015).

The Stauber Committee to Examine Ways to Promote Women in the Civil Service was established in 2013. The committee's recommendations deal with pay, bidding, women in senior positions, work-life balance, leadership courses, etc.

Of the highest-ranking positions in the civil service, $1.0 \%$ is staffed by women. A plan has been drawn up according to which, within five years, $21 \%$ of women will be at least at the highest level and one level below it, in government ministries and sub-units.

The sanction given to ministries that do not meet this goal is that they will not be permitted to recruit employees without the Exceptions Committee's approval. The problem is that there is a significant gap between women who bid for positions in the civil service. Though women make up $61 \%$ of state workers, only $18 \%$ get to the bidding stage.

Appropriate representation in relation to the appointment of a director-general of a government ministry should be proportionate to women's percentage in the civil service. The percentage of women in government ministries (21\%) does not 
represent their proportion in the general population and in the civil service. (Wexelman, 2015).

Current executives in Germany think the goal of improving the number of women in operational management should be achieved through mentoring programs, internal target agreements, including aspects of gender equality in the company's mandatory report, and modern human resource management, which takes into account the following (Wipperman, 2010):

1. Differing needs and potential of women and men in management positions

2. Promotion of career change and penetration into sectors that were previously only male

3. Encouragement of women to take leaps in their careers

Managers in the business world in Germany, both men and women, think that a change in the number of female managers in at the senior level is unlikely to happen without assistance from the law and government decrees. According to these managers, it will not be possible to balance the number of women in senior positions without politicians and business leaders in the economy promoting legislative measures to support this change. It is a process of changing social perceptions and cultural thinking patterns that will enable mobility between different gender roles in the workplace (Wipperman, 2010).

As previously mentioned, Deshe's idea is that if there are no women on the board, there would be no public offering on the stock exchange. There should be at least three women on the board or at least $25 \%$ of women out of all participants on the board of directors (Deshe, 2020).

\subsection{Worsening of Inhibiting Factors by the COVID-19 Crisis}

Since the beginning of 2020, a large part of the population has been forced to work remotely or has been laid off in some professions and industries due to the COVID19 epidemic. Women were at higher risk of suffering greater losses in profits, as today, many work in occupations in community and social services, education, library and training, office and administrative support, and personal services in larger percentages than men. In the female professions, many were suspended from work, laid off, or forced to work fewer hours. Some of the women even resigned from their positions in order to take care of children who were no longer in school, or elderly family members who were left without care (Payscale, 2020).

According to previous studies conducted by PayScale, some women's salaries dropped by $7 \%$ upon returning to work after an absence. Gender pay gaps for employees in positions with the same level of experience and training were 
significantly affected by the situation. Women make up $90 \%$ of the nursing profession, but are paid less than their male counterparts, even though they face the same significant health risks (Payscale, 2020).

Measures taken to prevent the spread of the pandemic, such as shutdowns and the limiting of crowds, have led to the halting of women's careers and career advancement. It is now more challenging to return to the work cycle in the following respects (Hasson and Ben Eliyahu, 2020):

1. Many women have been laid off from their jobs or taken out of the workplace due to job cuts.

2. Children did not return to school or only partially returned, and the expectation is that women will stay home with the children.

3. The number of jobs in fields considered "female" (education systems, restaurants, catering, and secretarial positions) has declined due to a decrease in necessity secondary to reduced activity.

4. As a result of deterioration in families' economic situation, there was a halt in the advancement of women who stayed at work. In Israel, one of the conditions for promotion is a master's degree, even promotion to management at the intermediate level. (Gilrovich, 2018) Therefore in families where women's advanced degree studies were planned (usually later in life than men's), the plans were disrupted due to budgetary considerations (college and university studies cost a lot of money).

The COVID-19 pandemic, which led to a reduction in economic activity, was reflected, among other things, in social-gender and economic inequality. Before the crisis, there were differences between women and men in different economic and labor market positions: compared to men, women, on average, work more in less profitable occupational industries and are mainly in lower positions in the organizational hierarchy (Hasson and Ben Eliyahu, 2020).

In March-April, women's share among job seekers was high, especially in the young age group. Up to the age of $24,39 \%$ of men were job seekers, compared to $61 \%$ of women. Between the ages of 25-64, the distribution of male job seekers was $45 \%$ compared to $55 \%$ of women. In general, among job seekers from all populations in Israel, $44 \%$ are men without a job, compared with $56 \%$ of women during this period (Hasson and Ben Eliyahu, 2020).

The COVID-19 crisis hit more those who had earned low wages even earlier. It is especially evident among women, who are more likely to receive low pay. Women's unemployment benefits were also lower than men's, in line with the initial salary. The median monthly wage of women whose work was stopped was 5,600 
NIS per month, only slightly higher than the minimum wage of 5,300 NIS, while the median salary for men was 7,500 NIS (Hasson and Ben Eliyahu, 2020).

For self-employed men and women in the economy, the average unemployment benefit for women was 3,231 NIS, about 1,400 NIS lower than that for men. The difference in the amount of the benefit reflects gender gaps in income before the COVID-19 crisis, as the median difference in monthly payment is about $42 \%$ in favor of men: 5,880 NIS for women compared to 10,081 NIS for men (Hasson and Ben Eliyahu, 2020).

Women are the majority among employees of the public systems that are essential for dealing daily with the consequences of COVID-19. The epidemic has revealed unfairness in a segregated and polarized labor market: a significant proportion of women in essential positions are also those whose wages are very low, and these positions are characterized by part-time work (Hasson and Ben Eliyahu, 2020).

The following are findings from a survey of women versus men in the labor market during the COVID-19 period, taken in early April 2020 (Keidar, 2020):

1. Compared to $32 \%$ of men, $48 \%$ of previously employed women said that they went on unpaid leave or that their work was terminated due to reductions. The big gap between women and men was in unpaid leave, whereby $37 \%$ of women were affected, compared to $24 \%$ of men.

2. Compared to $54 \%$ of men, $39 \%$ of women work the same amount as before.

3. Of those who continued to work, $21 \%$ of women continued as usual in the workplace, and $28 \%$ worked from home. On the other hand, among men, $35 \%$ continued as usual in the workplace, compared to $32 \%$ who worked from home.

4. The level of education greatly influenced the continued work of employees, both among men and women. Among women without an academic degree, $60 \%$ were dismissed or put on unpaid leave, compared to $37 \%$ of women with an academic degree. Few women without an academic degree work from home - only $11 \%$ of women without a degree worked from home or in the workplace, compared to $43 \%$ of women with an academic degree who worked from home.

5. Continued employment of young women was interrupted: $61 \%$ went on unpaid leave or were dismissed. Only $27 \%$ of the women who remained in full employment were aged $25-34$, whereas $45 \%$ of adults aged 35 plus stayed at work.

6. In the past, $36 \%$ of women were able to work from home more efficiently than in the workplace, compared with $46 \%$ of men. The inefficiency of working 
from home is likely due to the presence of children in the home: $44 \%$ of women without children could work efficiently from home.

This survey focused on gender research, adapted to the ratio between men and women in the labor market before the crisis. The sample consisted of 412 men and 348 women, representing 54\% men and $46 \%$ women in the sample. This sample represents the working population in Israel, which is currently divided into 53\% men and $47 \%$ women (Keidar, 2020)

\section{ConClusions}

The current situation is a gender imbalance in the workforce in general and in senior management in particular. The article reviews the literature to date about factors that prevent female managers from getting promoted to senior positions. The inhibitory factors are divided into external and internal influences, and classified according to aspects of sociological, economic, and female management perceptions, specifically compared to male management.

At the general level in the field of sociology, the literature review explores broad perceptions about the role of women in human culture and the world of work.

At the second level in the field of economics are factors that hinder female promotion, such as gaps in women's knowledge in the business field and their focus on the professional side and less on the managerial aspects. In occupations defined as female, there are less often senior ranks in management such that of vice president; due to this, women's salaries tend to be consistently lower than those of their male colleagues.

At the more specific level, which deals with human capital, the article addresses aspects of female management. Although women's voices are softer which does not play to their favor (Reardon, 2015) - allow this style to be more effective than authoritative male management.

In order to build the inclusion of additional women in business management systems, decisions must first be made to influence and take the necessary actions in legislation and enforcement (Wipperman, 2010).

At the political level, it has already been concluded that gender balance is an essential part of institutional organizational ethics. Thus was enacted the Gender Equality Act in Israeli government institutions, and procedures issued for its enforcement (Civil Service Commissioner, 2019).

Today, during the COVID-19 crisis, we are witnessing a worsening of women's situation in the workforce in general and in the promotion to senior positions in particular (Keidar, 2020). However, we do not yet know where this 
crisis will lead us. Will it lead to aggravation of the situation or change for the better? We currently cannot predict the future in this matter. Presumably, along with the difficulty is also the opportunity for women to break forth in entrepreneurship or identify opportunities that did not exist before within the current economy's limited scope.

In order to change the situation, actions must be taken on several fronts: education, culture, the economy, and legislation (Wipperman, 2010).

In the field of education, the expectation is for equal treatment of females and males. There need to be proposals for further studies in the transition to technology majors and encouragement of women to study in subjects that are considered masculine; in the university setting especially, female researchers and lecturers should be encouraged to be an equal part of the academic staff (Wang and Degol, 2017).

In workplace culture, language needs to be based on gender-neutral terms for gender equality in opportunity (European Parliament, 2018).

In the field of economics, promoting gender equality in the workplace means to create equal opportunities for men and women for admission to positions in all areas and in promotion to management and senior positions (Civil Service Commissioner, 2019).

In the field of legislation, the model that comes from the public sector for gender balance in government ministries and affiliates (Civil Service Commissioner, 2019) should be copied to the private and business sector. In the corporation, especially if it is traded on the stock exchange (Deshe, 2020), a new law may be enacted to implement wage equality. A related bill passed the first stage of approval by the Ministerial Committee for Legislative Affairs in the Israeli Parliament (Israeli Knesset, 2020). Enforcement would include a requirement that companies divulge in annual reports their efforts toward gender equality, which will be published in the media. Penalties would result if the balance is not established within a specified time from the moment the law comes out.

In order for women to overcome inhibitory factors in reaching senior positions, the economic reality needs to change so that they will be able to fund help for the management of the home and thus will be free to realize their high abilities at work and reach senior ranks. To promote women who are mothers to young children, and in order for there to be a gender balance in the workplace that reflects the proportion of women in the population, tax reliefs and grants for mothers must be allowed. The monetary compensation for unpaid labor such as housework will allow them to enter the workforce fully. The additional resources they will receive will allow them to consume outside services such as cleaning, laundry, babysitting, and cooking. These 
changes may help promote women to senior positions, prevent discrimination, make it easier for women to advance in their career paths, and allow women to apply their abilities and talents in all sectors of the economy (Amiran, 2017).

Changing the perception of different gender roles, combined with education expressed not only in institutions but also in other areas of life (such as art, advertisements, and social media), could also lead to change in women's status in the workplace. Future research will explore how management training and enrichment in business and engineering early in the education process can advance women to senior positions.

\section{ACKNOWLEDGEMENTS}

The author thanks Ossie Sharon, M.S., for her consultation and editing assistance. 


\section{REFERENCES}

1. Aharoni, Efrat (2015), Six senior executives in 100 companies: The dismal situation of senior executives in Israel, Globes, https://www.globes.co.il/news/article.aspx?did=1001046046, [Accessed 6.9.2020]

2. Amiran, Revital (2017), "Precisely when I did not expect it, my day came": Leah Fadida enters the Knesset, Maariv, https://www.maariv.co.il/news/politics/Article$\underline{\text { 60369, }}$, [Accessed 5.9.2020]

3. Axelrod, Ruth H. (2017), "Leadership and Self-Confidence", (in: Joan Marques and Satinder Dhiman-Eds., Leadership Today: Practices for Personal and Professional Performance), New York: Springer, pp.297-314.

4. Barry, Subha V. (2019), The Gender Gap at the Top: What's Keeping Women from Leading Corporate America? Working Mother Media, https://www.workingmother.com/sites/workingmother.com/files/attachments/2019 /06/women_at_the top_correct_size.pdf, [Accessed 29.8.2020]

5. Bar Zuri, Roni, Hannah Fisher and Asher Asis (1997), "Women in the New World of Work", Rubi Natanzon-Ed, Research submitted to the Abert Foundation, http://www.gandyr.com/wpcontent/uploads/2016/12/\%D7\%A0\%D7\%A9\%D7\%99\%D7\%9D\%D7\%91\%D7\%A2\%D7\%91\%D7\%95\%D7\%93\%D7\%94.pdf, [Accessed 2.9.2020]

6. Brayer-Garb, Ronna A., Dana Olmert, Orna Coussin and Yofi Tirosh (2017), "Capitalism and Gender: Feminist Issues with Market Culture." (in: Publications of the Center for the Advancement of Women in the Public Sphere (WIPS), Theory in Context Series), Jerusalem: Van Leer Institute Press and Hakibbutz Hameuchad.

7. Cambridge University (2020), Cambridge Dictionary. London: Cambridge University Press. https://dictionary.cambridge.org/dictionary/english/, [Accessed 20.9.2020]

8. Dagblad, Het A. (2019), Women less willing to travel far for work than men, Erasmus University Rotterdam, School of Economics, https://www.eur.nl/en/ese/news/women-less-willing-travel-far-work-men, [Accessed 19.9.2020]

9. Deshe, Galit (2020), Opinion: No woman, no stock issue? Globes, https://www.globes.co.il/news/article.aspx?did=1001319746, [Accessed 5.9.2020]

10. Duguid, Michelle (2011), "Female tokens in high-prestige work groups: catalysts or inhibitors of group diversification?" Organizational Behavior and Human Decision Processes, Vol. 116, No. 1, pp.104-115, https://www.sciencedirect.com/science/article/abs/pii/S0749597811000720, [Accessed 5.9.2020]

11. Eiran-Yona, Meital (2013), "An old organization, new fathers? Fighting officers between military careers and fatherhood", Gender, Vol. 2, pp.1-26.

12. European Parliament (2018), Gender-Neutral Language in the European Parliament, https://www.europarl.europa.eu/cmsdata/151780/GNL_Guidelines_EN.pdf, [Accessed 5.9.2020]

13. Flippin, Candace S. (2017), "The glass ceiling is breaking, now what?" Generations. Vol. 41, pp.34-42. 
14. Fischer Agneta H., Mariska E. Kret, Joost Broekens (2018), “Gender differences in emotion perception and self-reported emotional intelligence: A test of the emotion sensitivity hypothesis", PLoS One, Vol. 13, No. 1, e0190712, https://journals.plos.org/plosone/article/file?id=10.1371/journal.pone.0190712\&ty pe=printable, [Accessed 9.11.2020]

15. Fisher, Anne B. (1992), When Will Women Get to the Top? Fortune. Pp.44-56, https://money.cnn.com/magazines/fortune/fortune archive/1992/09/21/76886/inde $\underline{\text { x.htm, }}$ [Accessed 19.9.2020]

16. Gabdreeva, Guzel S. and Alisa R. Khalfieva, (2016), "The Features of Female Managers` Personality Traits in Organization", International Journal of Environmental \& Science Education, Vol. 11, No. 6, pp.1195-1203, http://www.ijese.net/makale indir/IJESE_243 article 573c5724ec058.pdf, [Accessed 20.9.2020]

17. Galka, Max (2015), A Visual History of Gender and Employment, Metrocosm, http://metrocosm.com/a-visual-history-of-the-gender-employment-gap/, [Accessed 6.9.2020]

18. Gallup (2015), State of the American Manager: Analytics and Advice for Leaders, https://www.gallup.com/services/182138/state-american-manager.aspx, [Accessed 20.9.2020]

19. Gilrovich, Michelle (2018), To what extent does a master's degree contribute to the world of work, and when should it be done? Globes, https://www.globes.co.il/news/article.aspx?did=1001227743, [Accessed 6.9.2020]

20. Grant, Linda, Sue Yeandle and Lisa Buckner (2006), "Working below Potential: Women and Part-Time Work", Working Paper Series No. 40, Sheffield: Sheffield Hallam University, http://circle.group.shef.ac.uk/wpcontent/uploads/2018/05/WBPLeicester.pdf, [Accessed 29.8.2020]

21. Hasson, Yael and Hadas Ben Eliyahu (2020), "Behind the Numbers: Implications of the Corona on Women in Israel. Status No. 1," Jerusalem: Van Leer Institute, https://adva.org/wp-content/uploads/2020/06/corona-women-report.pdf, [Accessed 29.08.2020]

22. Hedreen, Siri (2019), “'Gendered' Jobs Are on the Decline, But Stereotypes Remain", Business News Daily, https://www.businessnewsdaily.com/10085-malefemale-dominated-jobs.html, [Accessed 1.9.2020]

23. Hermon, Ron, Hagai Porat, Yuval Feldman and Tamar Krichli-Katz (2018), "Occupational discrimination in Israel: a differentiated approach", Policy Research, Vol. 121, https://www.idi.org.il/media/11312/employmentdiscrimination-in-israel-a-differentiated-approach.pdf, [Accessed 2.9.2020]

24. Herrbach, Olivier and Karim Mignonac (2012), "Perceived Gender Discrimination and Women's Subjective Career Success: the Moderating Role of Career Anchors", Relations Industrielles / Industrial Relations, Vol. 67, No. 1, pp.25-50, https://www.jstor.org/stable/41634302?seq=1, [Accessed 19.6.2020]

25. Ilan, Shahar (2020), "One in five students has dropped out or is considering dropping out due to the corona crisis", Calcalist, https://www.calcalist.co.il/local/articles/0,7340,L-3837117,00.html, [Accessed 18.9.2020]

26. International Finance Corporation (2013), IFC Jobs Study Assessing Private Sector Contributions to Job Creation and Poverty Reduction: Findings on Gender, 
https://www.ifc.org/wps/wcm/connect/2125f97c-da65-4fb0-aba7-

1d554bfe55bb/full-study-gender.pdf?MOD=AJPERES\&CVID=jRvG5JC, [Accessed 12.9.2020]

27. Israeli Civil Service Commissioner (2019), Division of Gender Equality, Civil Service Commission. https://www.gov.il/he/departments/Units/woman_unit, [Accessed 4.9.2020]

28. Israeli Civil Service Commissioner (2019), Gender Equality Report in the Civil Service https://www.gov.il/BlobFolder/reports/report-gender-equality-20152019/he/GenderEquality2015-2019.pdf , [Accessed 20.6.2020]

29. Israeli Knesset (2020), Equal Pay Bill for Male and Female Employees (Amendment - Obligation to Publish Annual Report), 5702-20, $23^{\text {rd }}$ Israeli Knesset. Internal No. 2085992, https://www.nevo.co.il/law html/law04/661_23 lst_570274.htm, [Accessed 4.9.2020]

30. Jalbert, Susanne E. (2010), Chapter 6: Women in the Economy, (in: Global Women's Issues: Women in the World Today), Victoria: BC Campus, https://opentextbc.ca/womenintheworld/chapter/chapter-6-women-in-theeconomy/, [Accessed 2.9.2020]

31. Keidar, Yarden (2020), The Impact of the Corona Crisis: Women - Men, Special Economic Survey, Jerusalem: Israel Democracy Institute, https://www.idi.org.il/blogs/special-economic-survey/march-april-2020/31818, [Accessed 4.9.2020]

32. Kramar, Robin (1998), "Managing diversity: beyond affirmative action in Australia", Women In Management Review, Vol. 13, No. 4, pp.133-142, https://www.emerald.com/insight/content/doi/10.1108/09649429810219763/full/ht $\underline{\mathrm{ml}}$, [Accessed 20.9.2020]

33. Krupnick, Catherine G. (1985), Women and Men in the Classroom: Inequality and Its Remedies, (in: On Teaching and Learning, Volume 1), Boston: Harvard University. http://ddi.cs.unipotsdam.de/HyFISCH/Informieren/WomenMenClassroomKrupnick.htm, [Accessed 2.9.2020]

34. Levanon, Asaf, Paula England, Paul D. Allison (2009), “Occupational Feminization and Pay: Assessing Causal Dynamics Using 1950-2000 U.S. Census Data," Social Forces, Vol. 88, No. 2, pp.865-92, https://academic.oup.com/sf/article-abstract/88/2/865/2235342, [Accessed 11.11.2020]

35. Milliken, Francis J, Elizabeth W. Morrison and Patricia F. Hewlin (2003), An exploratory study of employee silence: issues that employees don't communicate upward and why, New York University, Stern School of Business, Department of Management and Organizational Behavior, http://homepages.se.edu/cvonbergen/files/2012/12/AN-EXPLORATORYSTUDY-OF-EMPLOYEE-SILENCE_IISSUES-THAT-EMPLOYEES-DONTCOMMUNICATE-UPWARD-AND-WHY.pdf, [Accessed 29.8.2020]

36. Ministry of Economy and Industry, Strategy and Policy Planning Division (2019), Promoting Women in Entrepreneurship, Industry, and Business, https://bit.ly/33M4m4W, [Accessed 29.8.2020] 
37. Ministry of Education (1959), Compulsory Education and State Education Regulations, https://bit.ly/2RK8L2k, [Accessed 19.9.2020]

38. Mizrahi Simon, Shelly (2015), "Women in Israel: Key Issues Submitted to the Committee for the Advancement of the Status of Women and Gender Equality", Document in preparation for the 20th "Knesset" Israeli Parliament, Research and Information Center, https://main.knesset.gov.il/Activity/Info/MMMSummaries19/Women.pdf, [Accessed 29.8.2020]

39. Mohr, Tara S. (2014), "Why Women Don't Apply for Jobs Unless They're $100 \%$ Qualified”, Harvard Business Review, https://hbr.org/2014/08/why-women-dontapply-for-jobs-unless-theyre-100-qualified, [Accessed 29.8.2020]

40. Morrison, Ann M. (1992), The New Leaders: Guidelines on Leadership Diversity in America, San Francisco: Jossey Bass,

41. Oakley, Judith G. (2000), "Gender-based Barriers to Senior Management Positions: Understanding the Scarcity of Female CEOs", Journal of Business Ethics, Vol. 27, pp.321-334, https://doi.org/10.1023/A:1006226129868, [Accessed 29.8.2020]

42. Olson, Ann (2013), "The Theory of Self-Actualization”, Psychology Today. https://www.psychologytoday.com/us/blog/theory-andpsychopathology/201308/the-theory-self-actualization, [Accessed 20.6.2020]

43. Orbach, Meir (2016), "Women make up only $26 \%$ of the Israeli high-tech industry", Calcalist, https://www.calcalist.co.il/internet/articles/0,7340,L3682780,00.html, [Accessed 6.9.2020]

44. Payscale (2020), The State of the Gender Pay Gap 2020, Payscale, https://www.payscale.com/data/gender-pay-gap, [Accessed 6.9.2020]

45. Piterman, Hannah (2008), "The Leadership Challenge: Women in Management", Australian Government Department of Social Services, https://www.dss.gov.au/sites/default/files/documents/05 2012/report_march08.pdf , [Accessed 6.9.2020]

46. Reardon, Jayne (2015), How to stop the silencing of women in the workplace, World Economic Forum, https://www.weforum.org/agenda/2015/02/how-to-stopthe-silencing-of-women-in-the-workplace/, [Accessed 1.9.2020]

47. Rout, Usha R. and Jaya K. Rout (2002), Chapter 3: Occupational stress, (in: Usha R. Rout and Jaya K. Rout-Eds., Stress management for primary health professionals), New York: Kluwer Academic/Plenum Publishers, pp.25-39, https://www.springer.com/gp/book/9780306472404, [Accessed 11.11.2020]

48. Sasson-Levi, Orna and Chen Misgav (2017), "Exploring Gender in Israel in the Early 21 st Century:

49. Between neoliberalism and neo-colonialism", Megamot, Vol. 51, No. 2, pp.165206, https://bit.ly/35Ufi34, [Accessed 20.6.2020]

50. Schweitzer, Linda, Eddy Ng, Sean Lyons and Lisa Kuron (2011), "Exploring the Career Pipeline: Gender Differences in Pre-Career Expectations", Relations Industrielles / Industrial Relations, Vol. 66, No. 3, pp.,422-444, www.jstor.org/stable/23078364, [Accessed 29.8.2020]

51. Stocking, Barbara (2016), "Male-dominated workplace culture alienates talented women", Financial Times, https://www.ft.com/content/51c81a8c-69d9-11e6a0b1-d87a9fea034f, [Accessed 29.8.2020] 
52. Wall Street Journal (2020), "The invisible wall: this is how women are paved out of the safe path for CEOs", Globes, https://www.globes.co.il/news/article.aspx?did=1001317915, [Accessed 6.9.2020]

53. Wang, Ming-Te and Degol, Jessica L. (2017), "Gender Gap in Science, Technology, Engineering, and Mathematics (STEM): Current Knowledge, Implications for Practice, Policy, and Future Directions", Educational Psychology Review, Vol. 29, No. 1, pp.119-140, https://www.ncbi.nlm.nih.gov/pmc/articles/PMC5404748/, [Accessed 6.9.2020]

54. Wexelman, Shelly (2015), Follow-up Report: Implementation of a government decision on promotion and integration of women in the civil service on the basis of Government Resolution 1697 dated 2014.6.8: adoption of the recommendations of the Committee for the Advancement of Women in the Civil Service, (in: "Monitor" Project of the Center for Citizen' Empowerment in Israel [CECI]), https://www.ceci.org.il/sites/citizens/UserContent/files/monitorreport/monitor1697 .pdf, [Accessed 4.9.2020]

55. Wipperman, Carsten (2010), Women in Executive Positions: Barriers and Bridges, Federal Ministry for Family Affairs, Senior Citizens, Women and Youth, Heidelberg: Sinus Sociovision, https://www.bmfsfj.de/blob/93878/24ef73d6200f47c4b5c25702af30bec4/frauenin-fuehrungspositionen-englisch-data.pdf, [Accessed 1.9.2020]

56. Zainzinger, Vanessa (2012), "Age and motherhood are biggest barriers for working women”, Real Business, https://realbusiness.co.uk/age-and-motherhoodare-biggest-barriers-for-working-women/, [Accessed 18.9.2020] 